\title{
STRUCTURE CHARACTERIZATION OF FLAVONOID Aglycone FROM ETHYL ACETATE EXTRACT OF Rhodomyrtus tomentosa (AIT) HASSK
}

\author{
Rizal Fahmi ${ }^{1}$, Yunazar Manjang1, Dachriyanus ${ }^{2}$ and Nordin Lajis ${ }^{3}$ \\ ${ }^{1}$ Faculty of Mathematics and Natural Science, Andalas University, Padang, Indonesia \\ ${ }^{2}$ Faculty Pharmacy, Andalas University, Padang, Indonesia \\ ${ }^{3}$ Institute of BioScience, University Putra Malaysia, Malaysia \\ Email : fahmi alhadiid1991@yahoo.com
}

\begin{abstract}
A flavonoid aglycone, 5-hydroxy-3,3',4,5',7 pentamethoxy - flavone (Combretol), an antibacterial compound of ethyl acetate extract from the leaves of Rhodomyrtus tomentosa. The structure of this compound was established based on spectroscopic analyses and comparison with the related compound. The structure characterization of this compound will be discussed.
\end{abstract}

Keywords: Rhodomyrtus tomentosa, flavonoid aglycone, structure characterization

\section{REFERENCES}

1. I. H. A. Burkill, Dictionary of the Economic product of the Malay Peninsula. Government of Malaysia and singapore by the ministery of Agriculture and Cooperatives, Kualalumpur, (1996).

2. Hou, Aijun, Wu, Yangjie, and Liu, Yanze, Flavone Glicosides and an Ellagitanin from Downy rosemyrtle (Rhodomyrtus tomentosa), Zhongcaoyao, 30 (9), 645-648, (1999).

3. Liu, Yan Ze, Hou, Aijun, Ji, Chun Ru, and $\mathrm{Wu}$, Yangjie, A New C-Glycosidic Hidrolyzable Tannin from Rhodomyrtus tomentosa, Chin, Chem, Lett., 8 (1): 39-40 (1997)..

4. Liu, Yan $\mathrm{Ze}, \mathrm{Hou}$, Ai Jun; Ji, Chun $\mathrm{Ru}$; $\mathrm{Wu}$, Yang Jie, Isolation and structure of Hydrolysable Tannins from Rhodomyrtus tomentosa, Tianran Chanwu Yanjiu yu Kaifa, 10 910; 14-19 (1998).

5. Hui, Wai-Haan, Li, Man-Moon and Luk Kong, triterpenoid and steroid from Rhodomyrtus tomentosa, Phytochemistry, 14 93): 833-834 (1975).

6. Hui, Wai-Haan and Li, Man-Moon ., Two New Triterpenoid from Rhodomyrtus tomentosa, Phytochemistry, 15 (11): 1741-1743 (1976).

7. J.B. Harborne (1994), The Flavonoids Advances in Research since 1986, Chapman and hall, London. 310.

8. P.K. Agrawal, Carbon- ${ }^{13} N M R$ of Flavonoids, Elsevier, Amsterdam. 164-165, (1989).

9. R.Fahmi,.,Y.Manjang.,Dachriyanus.,NH.La jis., Bull.Soc.Nat Prod.Chem., (10)., 1-4. (2010). 